\title{
A rare case of bilateral testicular epidermoid cysts in a patient with Klinefelter's syndrome
}

\section{Sagi SV, Hikmat M, Oyibo SO, Rajkanna J \\ Department of Endocrinology, Peterborough City Hospital, Peterborough, UK}

\section{Introduction}

Klinefelter's syndrome (KFS) is associated with an increased risk of certain malignancies; including leukaemia, breast cancer and mediastinal germ cell tumours. Testicular tumours are uncommon. Epidermoid cysts are benign tumours of hair-growing areas. Testicular epidermoid cysts are very rare and account for $1-2 \%$ of all testicular tumours. We report a rare case of bilateral epidermoid cysts in a patient with Klinefelter's syndrome.

\section{Case}

A 30-year-old man diagnosed with Klinefelter's syndrome in childhood was referred to the endocrine outpatient clinic to initiate testosterone replacement in view of worsening symptoms of tiredness and erectile dysfunction. On physical examination he had gynecomastia and both his testes were very hard with irregular surfaces.

\section{Investigation and results}

His laboratory tests showed elevated Luteinising Hormone and Follicle Stimulating Hormone levels and a very low testosterone level $(2.7 \mathrm{nmol} / \mathrm{L})$ consistent with primary gonadal failure. An ultrasound scan of his testes demonstrated bilateral solid testicular masses with no blood flow seen within the lesions. There was very little identifiable normal testicular tissue seen within the right testis (the right testicular mass measured $34 \mathrm{~mm} \times 27 \mathrm{~mm} \times 23 \mathrm{~mm}$ and the left testicular mass measured $9 \mathrm{~mm} \times 5 \mathrm{~mm}$ ). A CT scan of his chest, abdomen and pelvis, along with serum alphafetoprotein and beta-human chorionic gonadotrophin levels were all normal.
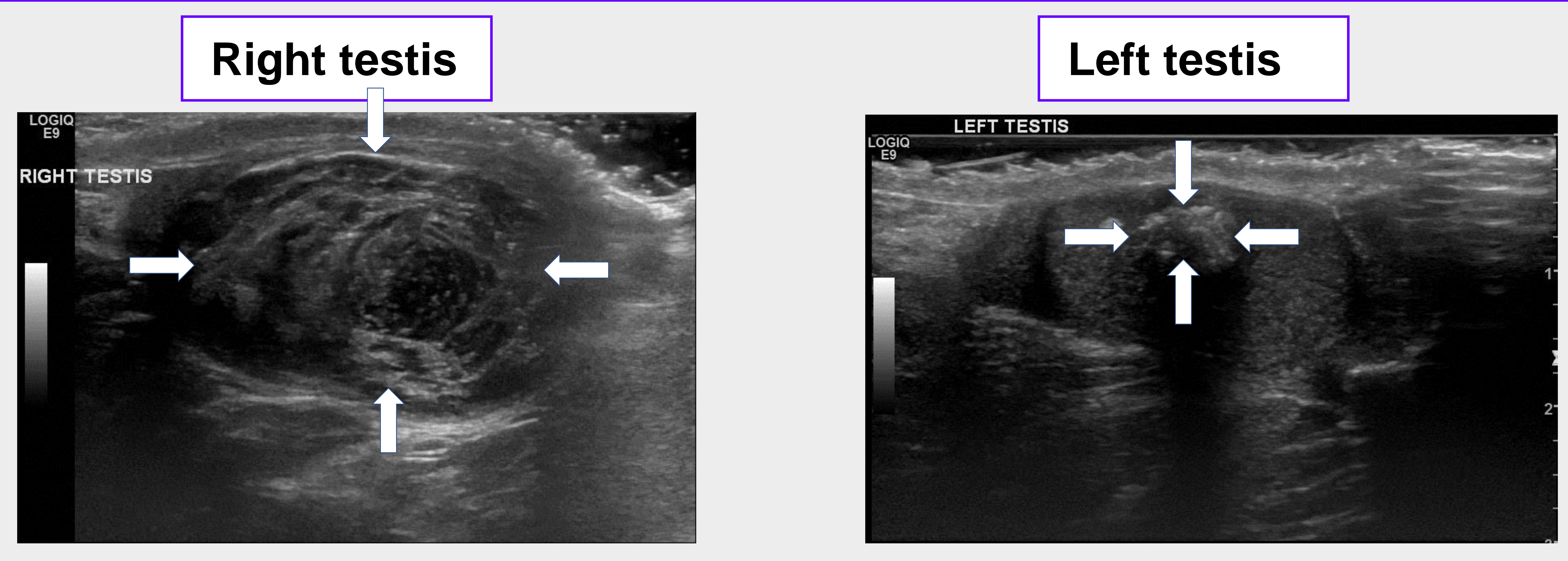

\section{Management}

He went on to have a right orchiectomy. The histology revealed features characteristic of an epidermoid cyst. The left testis remained unchanged over three years of ultrasound surveillance. The patient was put on testosterone replacement.

\section{Discussion}

There are very few cases of testicular epidermoid cyst reported in the literature and even fewer cases are bilateral or found in patients with Klinefelter's syndrome. The decision between surgical or conservative management is controversial because of the differential diagnosis, the possibility of diagnostic errors and the issues of fertility. 